\title{
Prevalence and correlates of HIV infection in a cohort of male injection drug users in Delhi
}

\author{
Waimar Tun \\ Population Council \\ Vartika Sharma \\ Population Council \\ Mary Philip Sebastian \\ Population Council \\ Ira Madan \\ Amita Yadav
}

See next page for additional authors

Follow this and additional works at: https://knowledgecommons.popcouncil.org/departments_sbsr-hiv

Part of the Demography, Population, and Ecology Commons, Health Policy Commons, Health Services Research Commons, Immune System Diseases Commons, International Public Health Commons, Medicine and Health Commons, and the Virus Diseases Commons How does access to this work benefit you? Let us know!

\section{Recommended Citation}

Tun, Waimar, Vartika Sharma, Mary Philip Sebastian, Ira Madan, Amita Yadav, Meredith Sheehy, Dean Lewis, Ibou Thior, and Avina Sarna. 2012. "Prevalence and correlates of HIV infection in a cohort of male injection drug users in Delhi," Research update. New Delhi: Population Council. 


\section{Authors}

Waimar Tun, Vartika Sharma, Mary Philip Sebastian, Ira Madan, Amita Yadav, Meredith Sheehy, Dean Lewis, Ibou Thior, and Avina Sarna 


\section{Prevalence and Correlates of HIV Infection in a Cohort of Male Injection Drug Users in Delhi}

DECEMBER 2012

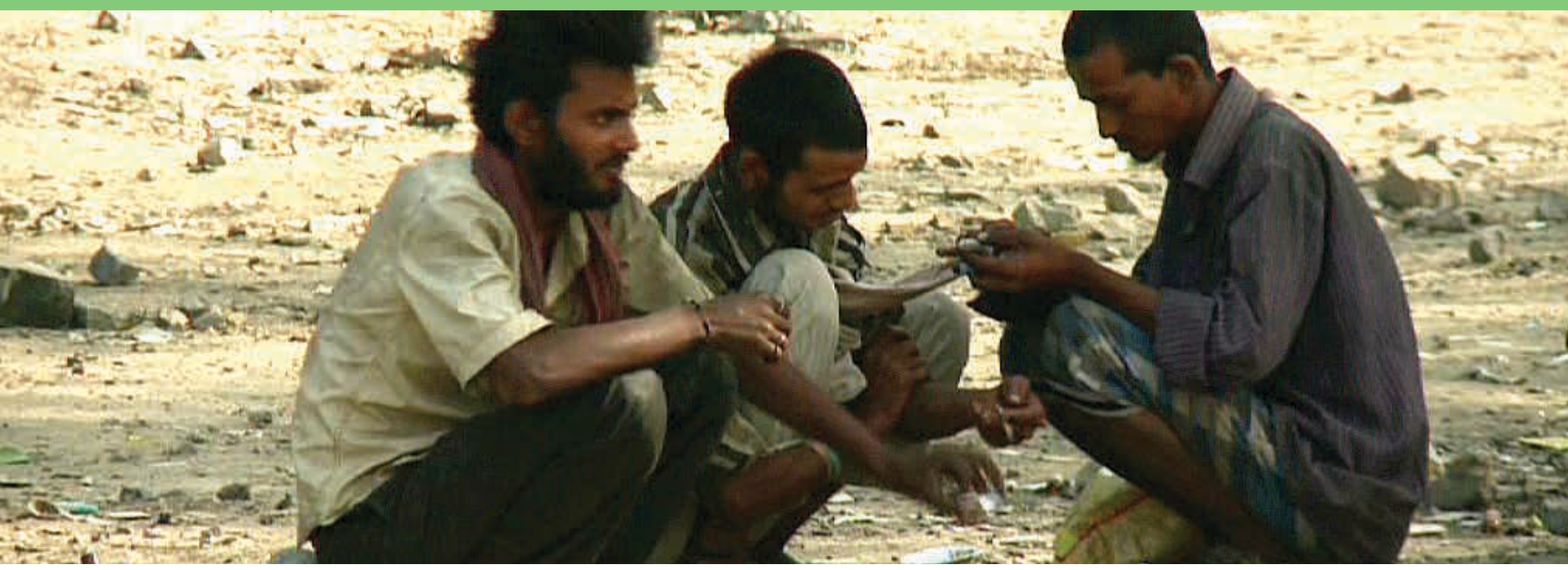

India has one of the largest injecting drug user (IDU) populations in the world, estimated at 177,000 nationally and 17,000 in Delhi alone..$^{1,2}$ Injection practices such as needle sharing and drawing up drugs from a common container, and high-risk sexual behaviours such as having multiple partners and unprotected sex fuel the HIV epidemic among IDUs as well as their injecting and sex partners.

Reducing sexual and injection risk behaviours is critical to controlling the HIV epidemic among IDUs and their sex partners. Evidence indicates that HIV-positive IDUs reduce transmission behaviours upon learning their HIV status. ${ }^{3-7}$ Thus, HIV testing offers an entry point into targeted services for IDUs that may reduce risk behaviour. The Population Council, in collaboration with the Sahara Centre for Residential Care and Rehabilitation (Sahara) and Arise-Enhancing HIV Prevention Programs for At-Risk Populations is implementing a project to avert HIV infections among IDUs and their sexual and injecting partners in Delhi by increasing the uptake of HIV counselling and testing (HCT) and increasing HIV prevention and harm reduction service coverage. As part of the evaluation for this project, we conducted a baseline assessment of HIV infection among male IDUs to understand the correlates of HIV infection and high risk injection practices and sexual behaviour among male IDUs.

\section{Study Methodology}

The baseline assessment was undertaken from May to October 2011 at five sites within Delhi. The sites were operated by Sahara Centre for Residential Care and Rehabilitation. Participants were recruited through peer-referral, targeted outreach by outreach workers, and walk-ins. To be eligible, participants had to be at least 18 years of age, residing in and around Delhi, and injected at least once in the last three months. Trained research interviewers administered

This material was produced under Arise-Enhancing HIV Prevention for At-Risk Populations. Arise implements innovative HIV prevention initiatives for vulnerable communities, with a focus on determining cost-effectiveness through rigorous evaluations. 
a close-ended questionnaire in Hindi to collect data on socio demographic characteristics, injecting practices, sexual behaviours, knowledge of HIV and utilization of harm reduction services. All participants were offered HIV testing based on three rapid tests per national HIV testing guidelines.

\section{Study Population}

A total of 3,792 males, including 10 transgenders, and 26 females were recruited into the study. Overall, 53.6 percent of the IDUs were recruited through targeted outreach, 26.3 percent through peer referral and 20.1 percent were walk in clients. Due to the small numbers recruited, female IDUs were not included in the analysis.

The median age was 30 years, 52.1 percent were never married, and 56.9 percent were less than 30 years of age. About one-half (48.9 percent) were illiterate, 56.3 percent were daily wage earners, and 27.5 percent were self-employed. IDUs were primarily either living in a family/relative's home (43.1 percent) or in the street, slum or public area (40.3 percent).
HIV-positive IDUs were more likely to report high risky injecting drugs behaviour compared to HIV-negative IDUs

HIV-positive participants were more likely to have been using drugs (injecting and non-injecting) drugs for longer periods than HIV-negative IDUs; 53.3 percent HIV-positive IDUs were using drugs for more than 11 years compared to 46.9 percent of HIV-negative participants ( $p<0.001)$. HIV-positive male IDUs were also more likely to report unsafe injection practices in the last one month compared to HIV-negative male IDUs (Figure 1). HIV-positive IDUs were also more likely to access harm reduction services, particularly needle and syringe exchange program (NSEP) services (45.3 percent vs. 30.1 percent; $p<0.001$ ), compared to HIV-negative IDUs.

\section{Lower sexual activity reported by HIV-posi- tive IDUs compared to HIV-negative IDUs}

Overall sexual activity was low; 36.6 percent of participants reported sexual intercourse in the last three months. HIV-positive IDUs were less sexually active, and reported unsafe sex with male and female partners less frequently than HIV-negative IDUs (Figure 2). A fairly high proportion (15.3 percent) of HIV-positive IDUs reported unsafe sex with a regular female partner.

\section{Key Findings}

\section{High acceptability of HIV testing among the IDUs}

Almost all (95.4 percent) of male IDUs were tested; only 175 remained untested due to refusal or blood draw not being possible. Only 37.6 percent had previously been tested for HIV. Even more worrisome is that one-half (52.5 percent) of those who tested HIV positive in this study had never been tested before.

\section{High prevalence of HIV among the IDUs}

HIV prevalence amongst those tested was 21.9 percent. This is a much higher prevalence of HIV infection than the 10 percent reported by the sentinel surveillance conducted in Delhi in 2006 and higher than the national HIV prevalence estimates (9.2 percent) for IDUs in $2010 .{ }^{8}$ The HIV prevalence of 21.9 percent is similar to the self-reported HIV prevalence we documented in our previous study among male IDUs in Delhi in 2006. ${ }^{9}$
Figure 1 Injection behaviours of HIV-positive and HIV-negative male IDUs in Delhi, 2011

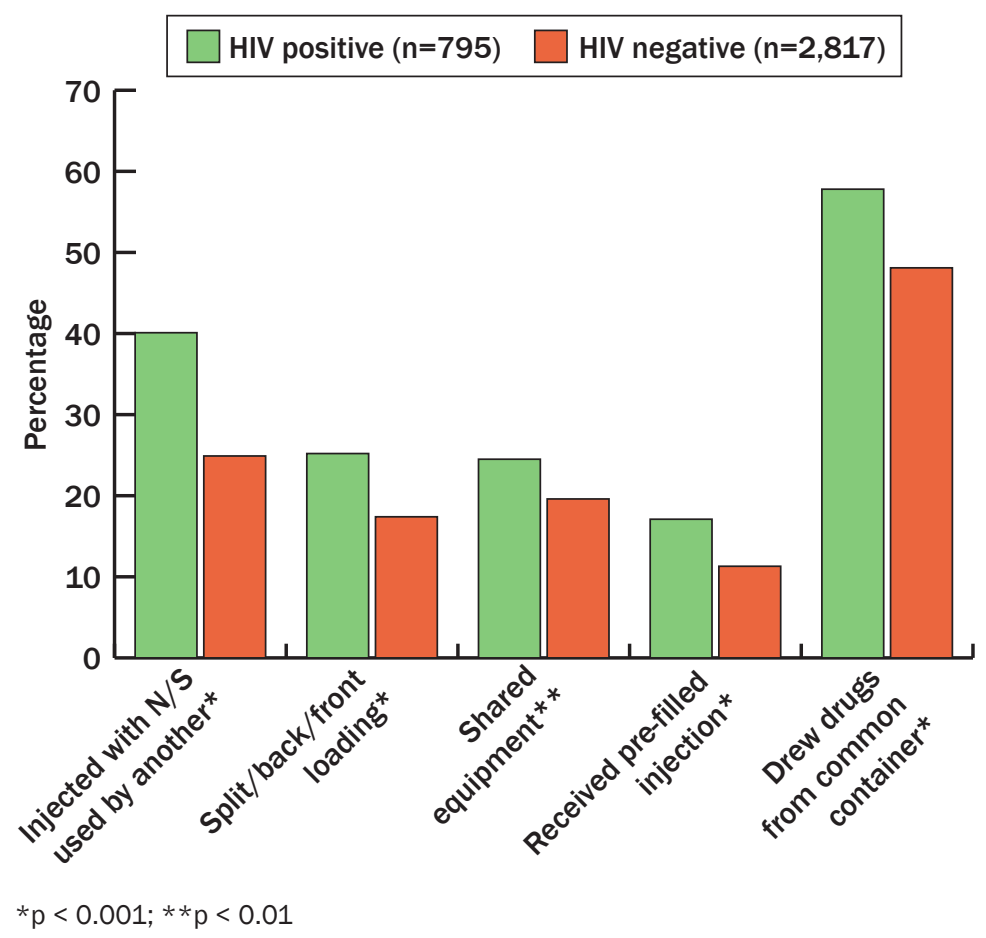


Figure 2 Sexual behaviours in the last three months of HIV-positive and HIV-negative male IDUs in Delhi, 2011

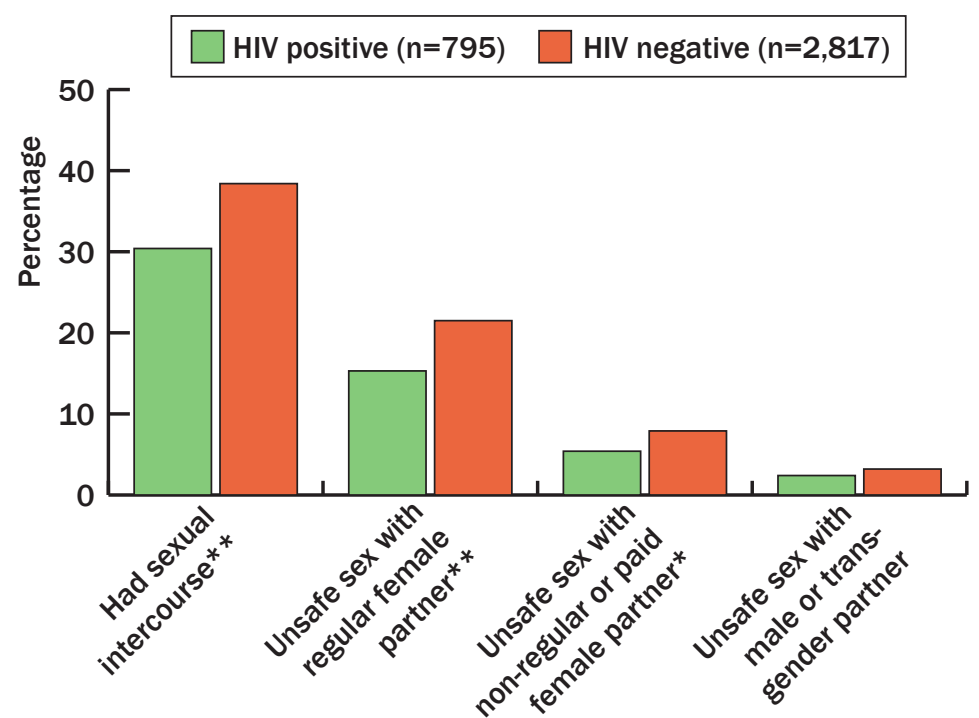

other facilities such as abscess care and NSEP. Targeted intervention programs for IDUs require HIV testing for IDUs at six month intervals. ${ }^{10}$ Further, one-half of those who tested positive in this study had never been tested previously. Undiagnosed HIV infection impedes the prevention efforts and access to treatment and care for HIV-positive IDUs. It is imperative that prevention programmes emphasize and facilitate HIV testing in this population.

We found that unsafe injection practices were reported more frequently by HIV-positive IDUs. Information, education and counselling needs to be strengthened to emphasize safer injecting practices.
$* p<0.05 ; * * p<0.001$

\section{Injection drug use behaviours were the dominant risk factors for HIV infection com- pared to sexual behaviours}

In multivariate analysis, after controlling for demographic variables, those who had been using drugs (non-injecting or injecting) longer, engaging in highrisk injection practices', and having accessed harm reduction servicesii were more likely to be HIV infected. Alternatively, those who drank alcohol more frequently and engaged in unsafe sex with female partners (compared to those not having any sex with a female partner) were less likely to be HIV infected.

\section{Program Implications and Recommendations}

The results of the baseline assessment as a part of the longitudinal study highlighted some key issues for HIV prevention program in Delhi. Inspite of a massive scale up of HIV counselling and testing services, the study reveals that less than 40 percent participants reported prior HIV testing despite having accessed

\footnotetext{
'An index was created for risky injection practices. The index includes (i) Using used needle or syringe; (ii) Back/front loaded/split drugs; (iii) Shared vial/cooker/container/cotton/filter/water; (iv) Received pre-filled injection; (v) Drew up drugs from common container.

iHarm reduction services include NSEP services, abscess care, de-addiction services and opioid substitution therapy.
}

Table 1 Correlates of HIV-positive status among male IDUs in Delhi, 2011

\begin{tabular}{|c|c|c|}
\hline Variable & $\begin{array}{c}\text { Multivariate } \\
\text { adjusted } \\
\text { odds ratio }\end{array}$ & $\begin{array}{c}95 \% \\
\text { confidence } \\
\text { interval }\end{array}$ \\
\hline \multicolumn{3}{|c|}{ Time since initiating drug use } \\
\hline$\leq 1$ year & 1.00 & \\
\hline $2-5$ years & 2.02 & $1.09-3.73$ \\
\hline $6-10$ years & 2.81 & $1.55-5.11$ \\
\hline$\geq 11$ years & 3.35 & $1.84-6.11$ \\
\hline \multicolumn{3}{|c|}{$\begin{array}{l}\text { Risky injection behaviour in } \\
\text { last one month (5-item })^{\mathrm{a}}\end{array}$} \\
\hline No & 1.00 & \\
\hline Yes & 1.60 & $1.33-1.91$ \\
\hline \multicolumn{3}{|c|}{$\begin{array}{l}\text { Utilized services in last } 3 \\
\text { months }^{\text {b }}\end{array}$} \\
\hline No & 1.00 & \\
\hline Yes & 1.32 & $1.11-1.58$ \\
\hline \multicolumn{3}{|c|}{ Current alcohol use (average) } \\
\hline Never & 1.00 & \\
\hline$\leq 2$ times/week & 0.67 & $0.55-0.82$ \\
\hline$\geq 3$ times/week & 0.74 & $0.54-1.01$ \\
\hline \multicolumn{3}{|l|}{ Prior HIV testing } \\
\hline No & 1.00 & \\
\hline Yes & 1.60 & $1.35-1.91$ \\
\hline \multicolumn{3}{|c|}{$\begin{array}{l}\text { Unsafe sex with any female } \\
\text { partner in last } 3 \text { months }^{c}\end{array}$} \\
\hline No sex & 1.00 & \\
\hline Safe sex & 1.90 & $0.66-1.21$ \\
\hline Unsafe sex & 0.69 & $0.55-0.86$ \\
\hline
\end{tabular}

Model is adjusted for age, education, marital status, religion, regional origin, accommodation, and income.

alncludes: (i) Using used needle or syringe; (ii) Back/front loaded/split drugs; (iii) Shared vial/cooker/container/cotton/filter/water; (iv) Received pre-filled injection; (v) Drew up drugs from common container. 'Includes needle and syringe exchange program services, abscess care, de-addiction services and opioid substitution therapy. Includes regular, non-regular or paid. 
Indeed, we found that HIV-positive IDUs were more likely to access NSEP services. Utilization of NSEP services does not necessarily translate into safe behaviours as HIV-positive IDUs were more likely to report unsafe injection practices. HIV-positive IDUs also reported more frequent injections and thus would require a larger supply of needles and syringes. It is possible that while HIV-positive IDUs were more likely to access NSEP services, it may not be possible for them to obtain a sufficient supply of clean needles. Programs need to ensure that HIV-positive IDUs are getting sufficient supply of sterile needles and syringes and that they are in fact using them.

It is of concern that nearly one out of five HIV-positive IDUs reported unsafe sex with a regular female partner. The risk of onward HIV transmission to a sex partner remains high. Therefore, it is critical for HIV prevention programmes for IDUs to include their sex partners (regular and non regular partners).

\section{References}

${ }^{1}$ National AIDS Control Organization, Government of India. 2011. "National AIDS Control Programme, Phase III, state fact sheets." New Delhi: NACO, Ministry of Health \& Welfare, Government of India.

${ }^{2}$ National AIDS Control Organization (NACO), Department of AIDS Control, Ministry of Health and Family Welfare, Government of India. 2010. “Annual report 2009-2010." New Delhi: NACO.

${ }^{3}$ Des Jarlais, D.C., T. Perlis, and V. Poznyak. 2004. "Characteristics of injecting drug users (IDUs) in different regions of the world: WHO Phase II Study," presented at International Conference on the Reduction of Drug Related Harm, Melbourne, Australia.

\begin{abstract}
${ }^{4}$ Des Jarlais, D.C., and S. Semaan. 2005. "Interventions to reduce the sexual risk behaviour of injecting drug users," International Journal of Drug Policy 16S: S58-S66.

${ }^{5} \mathrm{Grau}$, L.E. et al. 2011. "HIV disclosure, condom use, and awareness of HIV infection among HIV-positive, heterosexual drug injectors in St. Petersburg, Russian Federation," AIDS Behav 15(1): 45-57.

${ }^{6}$ Vanichseni, S. et al. 1992. "HIV testing and sexual behavior among intravenous drug users in Bangkok, Thailand," J Acquir Immune Defic Syndr 5(11): 1119-1123.

${ }^{7}$ Desenclos, J.C., G. Papaevangelou, and R. Ancelle-Park 1993. "Knowledge of HIV serostatus and preventive behaviour among European injecting drug users. The European Community Study Group on HIV in injecting drug users," AIDS 7(10): 1371-1377.

${ }^{8}$ National AIDS Control Organisation, Ministry of Health and Family Welfare, Government of India. 2006. National Behavioural Surveillance Survey (BSS) 2006-Men who have Sex with Men (MSM) and Injecting Drug Users (IDUs). New Delhi: NACO.

9Sarna A et al. 2012. "Assessment of unsafe injection practices and sexual behaviors among male injecting drug users in two urban cities of India using respondent driven sampling," Southeast Asian J Trop Med Public Health 43(3): 652-667.

${ }^{10}$ National AIDS Control Organization, Ministry of Health and Family Welfare, Government of India. 2007. Targeted Intervention Under NACP III: Operational Guidelines (Volume I-Core High Risk Groups). New Delhi: NACO.
\end{abstract}

Suggested citation: Tun, Waimar, Vartika Sharma, Mary Sebastian, Ira Madan, Amita Yadav, Meredith Sheehy, Dean Lewis, Ibou Thior, and Avina Sarna. 2012. "Prevalence and correlates of HIV infection in a cohort of male injection drug users in Delhi," Research Update. Delhi: Population Council. and technical support provided by PATH. The views expressed by the authors do not necessarily reflect the views of PATH, the Canadă Canadian Government, or the Canadian International Development Agency.
}

\section{(2) Population Council}

The Population Council confronts critical health and development issues-from stopping the spread of HIV to improving reproductive health and ensuring that young people lead full and productive lives. Through biomedical, social science and public health research in about 50 countries, the Council works with our partners to deliver solutions that lead to more effective policies, programs, and technologies to improve lives worldwide. Established in 1952 and headquartered in New York, the Council is a nongovernmental, nonprofit organization with an international board of trustees.

www.popcouncil.org

(C) 2012 The Population Council, Inc. 